Teología y Vida, Vol. XLV (2005), 352 - 373

Samuel Fernández E.

Profesor de la Facultad de Teología

\title{
'Ya no vivo yo, es Cristo que vive en mí' (Gál 2, 20). 'Ser Cristo' como clave de la vida del padre Alberto Hurtado
}

Al estudiar los escritos del Padre Alberto Hurtado (1), se comprueba que el versículo bíblico citado con mayor frecuencia es Gálatas 2, 20: "Vivo yo, ya no yo, es Cristo que vive en mí". Además, se encuentran múltiples afirmaciones que explicitan la centralidad de este ideal paulino en la espiritualidad cristiana, según el Padre Hurtado: "iQué simple resulta nuestra espiritualidad! Ser Cristo” (2). Estas observaciones indican a Gál 2, 20 como la clave de la espiritualidad del santo jesuita.

(1) Los escritos del Padre Alberto Hurtado están compuestos por los libros y artículos que él publicó durante su vida, y por una gran cantidad manuscritos inéditos, que incluyen apuntes de retiro, conferencias, homilías, apuntes personales, diarios de viajes, apuntes de clases, etc., que no tenía la intención de publicar y que hoy se conservan en el Archivo de la Provincia Chilena de la Compañía de Jesús (se trata de unas 10.000 páginas). Algunos de estos manuscritos han sido publicados por Mensaje y por el Padre Álvaro Lavín: El Padre Hurtado. Apóstol de Jesucristo, Santiago 1977; Vocación social del Padre Hurtado, apóstol de Jesucristo, Santiago 1978; El Padre Hurtado, amigo y apóstol de los jóvenes, Santiago 1978; El Hogar de Cristo. Su amor a los pobres, Santiago 1979; Aspectos críticos en su ministerio sacerdotal, Santiago 1981; Su espiritualidad, 2a edición, Santiago 1982; La familia y los laicos, Santiago 1983. Además, J. Castellón, Diarios Espirituales del P. Hurtado, CEI, Cuaderno 118, Santiago 1999. Últimamente está siendo publicada, por el Centro de Estudios y Documentación 'Padre Hurtado', una serie de libros que, sin ser exhaustiva, da una visión bastante completa de los escritos inéditos. Los títulos son: Un disparo a la eternidad. Retiros espirituales predicados por el Padre Alberto Hurtado, S.J. Escritos inéditos del Padre Hurtado, S.J. Vol. 1. Introducción, selección y notas de Samuel Fernández Eyzaguirre, pbro. Ediciones Universidad Católica de Chile, Santiago 2002; Cartas e informes del Padre Hurtado, S.J., Escritos inéditos del Padre Hurtado, S.J. Vol. 2. Selección, presentación y notas de Jaime Castellón Covarrubias, S.J. Ediciones Universidad Católica de Chile, Santiago 2003; Moral Social. Obra póstuma del Padre Hurtado, S.J., Escritos inéditos del Padre Alberto Hurtado, S.J. Vol. 3. Edición, presentación y notas de Patricio Miranda Rebeco. Ediciones Universidad Católica de Chile, Santiago 2004; La búsqueda de Dios. Conferencias, artículos y discursos pastorales del Padre Alberto Hurtado, S.J. Escritos inéditos del Padre Hurtado, S.J. Vol 4. Introducción, selección y notas de Samuel Fernández Eyzaguirre, pbro. Ediciones Universidad Católica de Chile, Santiago 2005; Un fuego que enciende otros fuegos. Páginas escogidas del Padre Alberto Hurtado, S.J., Edición preparada por Samuel Fernández E., con la colaboración de Mariana Clavero et alii. Santiago, 2004. Citaremos de acuerdo a las ediciones impresas y cuando no la hay, se pone la referencia interna del Archivo.

(2) La unidad de nuestra espiritualidad, en Un disparo a la eternidad, p. 343 
Naturalmente, entre los escritos de Alberto Hurtado, no se encuentra ningún comentario sistemático de Gál 2, 20. Y, por tanto, será necesario ensayar una reconstrucción de la comprensión del texto paulino a partir de las muchas alusiones directas o indirectas que se conservan en sus escritos. Es el propósito del presente artículo.

\section{CENTRALIDAD DEL 'SER CRISTO’ EN LA OBRA DEL PADRE HURTADO}

En diversos escritos, el Padre Hurtado insiste en la centralidad del programa de San Pablo, expresado en Gál 2, 20. Ya han sido citadas las palabras finales de un texto que precisamente se llama La unidad de nuestra espiritualidad, y que corresponde a la plática conclusiva de un retiro al clero de la diócesis de San Felipe:

¡Qué simple resulta nuestra espiritualidad! Ser Cristo. Obrar como Cristo en cada circunstancia de mi vida, en lo que Cristo me ponga delante (3).

Y así como esta frase, se encuentran otras que destacan la centralidad de Gál 2, 20 en la vida cristiana: "Ser cristiano es ser incorporado a Cristo, imitar a Cristo, ser otro Cristo poder decir con verdad: ya no vivo yo... Cristo" (4). En Puntos de Educación afirma de modo rotundo: "Ser cristiano es ser Cristo" (5). Y ante los profesores de la Universidad Católica, declara:

Todo el evangelio y todos los santos [están] llenos de este ideal, que es el ideal cristiano por excelencia. Vivir en Cristo; transformarse en Cristo... San Pablo: Nada juzgué digno sino de conocer a Cristo y a este crucificado... Vivo yo; ya no yo, sino Cristo vive en mí (Gál 2, 20) (6).

Estas afirmaciones dejan clara la centralidad que Alberto Hurtado otorga al programa de Pablo, que considera el ideal cristiano por excelencia y su "única obligación" (7). Y así, "la santidad es dejarse tomar por Él, diciendo: 'Es Cristo el que vive en mí", (8). E incluso llega a afirmar: "Vivo yo; ya no yo; vive en mí, Cristo’. ¡Ser Cristo! He aquí todo mi problema. La razón de ser de la creación” (9). Llegar a 'ser Cristo' es, por tanto, la razón de ser de la creación (10).

(3) La unidad de nuestra espiritualidad, en Un disparo a la eternidad, p. 343.

(4) $\quad$ APH s33 y 27 , de 1939.

(5) Puntos de Educación, cap. XI

(6) Nuestra imitación de Cristo, en Un disparo a la eternidad, p. 79.

(7) Cf. "Mi única obligación es andar por la senda que es Cristo... vivir... imitarlo, en otra palabra ser Cristo" La unidad en nuestra espiritualidad, en Un disparo a la eternidad, p. 341.

(8) La vida de oración. Charla a la Fraternidad del Hogar de Cristo, en La búsqueda de Dios, p. 283.

(9) El obstáculo mayor del optimismo, en La búsqueda de Dios, p. 91.

(10) Esta afirmación hay que comprenderla a la luz del Principio y Fundamento ignaciano que afirma el carácter 'funcional' de toda la creación. El Padre Hurtado se basaba mucho en comentaristas de los EE tales como P. I. Casanovas, s.j., Comentario y explanación de los Ejercicios Espirituales de San Ignacio de Loyola, Barcelona, 1947, cf. tomo III, pp. 9-27. 
Un testimonio del P. Víctor Risopatrón, S.J., recogido en el proceso cognicional, confirma esta centralidad: 'Era un hombre de Dios: 'Otro Cristo'. Entregado sin reservas y sin horario. Quiso ser 'otro Cristo' y lo consiguió. Se asimiló totalmente a Cristo: los deseos de Cristo eran sus deseos; las palabras de Cristo eran sus palabras... Fue tanto lo que nos inculcó que debíamos ser 'otros Cristos', que yo quise serlo... y partí al Noviciado de la Compañía de Jesús...” (11).

Alberto Hurtado considera que el redescubrimiento de la centralidad del programa de Pablo es "una de las conquistas más profundas de nuestro siglo" (12). Ciertamente, se refiere al desarrollo de la teología del Cuerpo Místico que, naturalmente, es anterior a la publicación de la Encíclica Mystici Corporis Christi (1943), y que había estado precedida de importantes obras como la de Columba Marmión, Le Christ, vie de l'âme y al de Émile Mersch, Le Corps Mystique du Christ. Études de Théologie historique, a quien había tenido como profesor en Lovaina. Alberto Hurtado, en relación a esta doctrina, escribe en 1947:

Esta doctrina es la llamada a unificar toda la teología católica, como lo decía tantas veces uno de sus más ardientes vulgarizadores, el P. Emilio Mersch, S.J. Utilísimo sería que esta doctrina fuera estudiada a fondo en todas su consecuencias y en todas sus aplicaciones (13).

Los artículos de Mersch en Nouvelle Revue Théologique son abundantes e influyeron mucho en Alberto Hurtado durante su período de formación. En especial, La vie historique de Jésus et sa vie mystique (14). En esta teología encontramos la raíz de muchas afirmaciones del santo jesuita (15). Y se comprueba así, lo mucho que influyó el estudio de la teología en la configuración del ministerio del Padre Hurtado.

\section{LA ENCARNACIÓN COMO FUNDAMENTO DEL 'SER CRISTO'}

La posibilidad del hombre de 'ser Cristo' tiene su fundamento en la encarnación. 'Ser Cristo' significa pertenecer al Cuerpo Místico de Cristo, y esto se vuelve posible gracias a la encarnación. Así lo explica en un documento:

El Verbo, al encarnarse, quiso unir a Dios la naturaleza humana, y lo obtuvo en esa unidad maravillosa de la unión hipostática del Verbo con la naturaleza

(11) Un fuego que enciende otros fuegos, p. 116.

(12) La formación religiosa del niño en el hogar, APH s46 y 08: "Cristo no es un recuerdo histórico lejano, Cristo vive, vive en el cielo en la Eucaristía, y lo que es más, vive en mí, por la gracia. Una de las conquistas más profundas de nuestro siglo es esta comprensión íntima, profunda de la vida de Cristo en la mía: 'Ya no vivo yo, es Cristo quien vive en mí'...”.

(13) Humanismo Social, cap. I.

(14) NRT LX (1933), pp. 5-20. Pueden compararse las afirmaciones de este artículo con el retiro a profesores de la Universidad Católica en 1940, publicado en Un disparo a la eternidad, pp. 7985.

(15) Cf. J. Castellón, Identificarse con Jesucristo, sirviéndolo en su misión, II, 4.2.2, p. 50 (pro manuscripto). 
humana: unidad estrecha, inseparable, indisoluble. Dios pudo decir con absoluta verdad: tengo cuerpo, tengo alma, sufro, padezco... y un hombre que caminaba por las calles y tenía hambre, sed, dolor, podía decir: ;Soy Dios! (16)

Es decir, la primera unión entre la humanidad y la divinidad se da en el Hijo de Dios hecho hombre: Jesucristo. La unión hipostática, es decir, la unión de la naturaleza humana y divina en la persona del Verbo, fundamenta la comunión de propiedades (la clásica doctrina cristológica de la communicatio idiomatum) que expresa la realidad de esta unión. Pero esta unión va más allá de la persona misma del Verbo considerada individualmente. Continúa el mismo texto:

Pero esa unidad realizada en Cristo no era más que el principio de una unidad inmensamente mayor: quería el Padre que nosotros al unirnos a Cristo pasáramos a ser, por nuestra incorporación a Él, verdaderos hijos suyos. Quería llamarnos hijos, y que lo fuéramos en absoluta verdad, y para eso nos quería unidos a Cristo, quería vernos en Cristo (17).

La unión hipostática es fundamento de una más amplia: la unión de los hombres con Dios, en modo que los hombres también llegáramos a ser hijos de Dios: 'Los hombres, por gracia, pasan a ser lo que Jesús es por naturaleza: hijos de Dios' (18). Y por esta unión íntima con Cristo, podemos decir: ¡Cristo vive en mí! (cf. Gál 2, 20). La unión con Dios Padre se basa en nuestra incorporación a Cristo. Y esta unión alcanza a todos los hombres:

El Hijo de Dios, al unirse a una naturaleza humana, elevó en ella a todo el género humano. Cristo es el primogénito de una multitud de hermanos con quienes comparte su propia vida divina. Cristo es la Cabeza de un Cuerpo, el Cuerpo Místico, cuyos miembros somos o estamos llamados a serlo nosotros, sin limitación alguna de razas, de fortuna, ni de otra alguna consideración. Basta ser hombre para poder ser miembro del Cuerpo Místico de Cristo, esto es, para poder ser Cristo (19).

Todo el género humano es alcanzado por los efectos de la encarnación. Se aprecia una universalidad sorprendente, por cuanto el Padre Hurtado no tiene reparos en afirmar que 'basta ser hombre para poder ser miembro del Cuerpo Místico de Cristo, esto es, para poder ser Cristo', afirmación que tiene importantes consecuencias eclesiológicas, como se verá más abajo. Esta universalidad tiene amplias perspectivas. Así lo expresa en 1946, al regresar de Estados Unidos:

(16) Responsabilidad frente a la iglesia, en La búsqueda de Dios, p. 136. No hay datos para fijar la fecha de esta conferencia; por la referencia a la Misión de París y a la A.C., podría ser de 1944.

(17) Ibidem.

(18) Afirmación repetida muchas veces: Humanismo Social, cap. I; APH s19 y 27; s24 y 09; s25 y 04; s34 y 13 ; s51 y 20

(19) Moral Social, p. 204. 
La perfección sobrenatural, y aun natural, consiste en incorporarse más y más vitalmente a Cristo; en dejar que la Gracia que viene de Él se apodere de mí; que mis pensamientos, deseos y aspiraciones sean los suyos, que pueda yo decir con San Pablo: 'Mi vivir es Cristo'; 'Vivo yo, ya no yo, sino Cristo en mí' (20).

La repercusión universal de la encarnación implica que la perfección del hombre -aun su perfección natural- consista en su incorporación a Cristo. Esta misma universalidad cristológica se traspasa a la mariología: "María, por ser Madre de Cristo, dio a luz a todos los hombres" (21). Se trata, como él mismo lo dice, de aceptar la encarnación con todas sus consecuencias (22).

La insistencia en que el fundamento último de la unión con Jesucristo es la misma encarnación evita cualquier vestigio de pelagianismo, error que el Padre Hurtado consideraba latente en nuestra vida (23). La absoluta libertad de Dios en el designio de la encarnación destaca la iniciativa divina y, por tanto, la prioridad de la gracia de Cristo por sobre el esfuerzo humano. Se trata, según Alberto Hurtado, de 'dejar que la Gracia que viene de Cristo se apodere de mí' (24). Se trata, entonces, sobre todo, de remover los obstáculos, para que Cristo se abra paso y se apodere del hombre, destacando así la fuerza del amor de Jesucristo (25). Por eso asegura:

En mi vida sobrenatural, cuanto hay en mí de capacidad, de fuerza, de santidad, ¡de arriba viene! De Dios por Cristo. Vivo yo, ya no yo; vive Cristo en mí (Gál 2, 20). De Él desciende toda perfección; son más de Él que mías mis virtudes (26).

Queda clara, entonces, la iniciativa de la gracia en el programa de 'ser Cristo'. Esto no quiere decir que el hombre no participe en este proceso. El Padre Hurtado evita tanto el pelagianismo como el quietismo (27). Esta unión a Cristo no es homogénea ni automática: alcanza 'de derecho' a todos los hombres, y está llamada a desarrollarse 'de hecho' y en diversos grados (28), e incluso se puede perder:

(20) Meditación del Reino. 'Amor', en Un disparo a la eternidad, p. 65.

(21) APH s50 y 08. La relación personal con María, también está en función de Cristo: "María es Madre mía en cuanto yo estoy unido con Cristo su Hijo Unigénito. La maternidad de María es consecuencia de mi unión mística con Jesús”, Morir, meditación sobre el pecado, en Un disparo a la eternidad, p. 53.

(22) Cf. Humanismo Social, cap. I; Moral Social, p. 204.

(23) Cf. Vie spirituelle des militants, $A P H$ s20 y 29. El tema del pelagianismo lo enfrentó en un documento escrito para la AC, llamado Medios divinos y Medios humanos.

(24) Cf. Meditación del Reino. 'Amor', en Un disparo a la eternidad, p. 65.

(25) Cf. Consagración hombres al Sgdo. Corazón, APH s45 y 11: "De repente el amor apasionado de Cristo que se abre paso y se apodera del alma, y del pobrecito pecador hace un santo y alegra sus dolores y los hace llegar a decir en pocos días, a veces en pocas horas: Ya no vivo yo, es Cristo Jesús quien vive en mí... Oh fuerza admirable del amor de Cristo".

(26) Contemplación para alcanzar amor, $A P H$ s38 y 17.

(27) Cf. Vida Sacramental, $A P H$ s 39 y 10.

(28) Cf. Mes de María 1946, APH s51 y 20: "Desde la Encarnación y por la Encarnación todos los hombres estamos de derecho y muchos de hecho unidos a Cristo. Solo los condenados, excluidos de esta unión". Además, insiste en que todos los hombres 'somos o estamos llamados' a ser miembros del Cuerpo místico de Cristo, cf. Humanismo Social, cap. I; Moral Social, p. 204. 
La única derrota consiste en dejar de ser Cristo por la apostasía o por el pecado, la primera lo expulsa de Cuerpo místico, la segunda lo hace un miembro muerto (29).

Estas afirmaciones nos invitan a reflexionar acerca de la naturaleza de la unión que se produce, a partir de la encarnación, entre Cristo y cada hombre.

\section{NATURALEZA DE LA UNIÓN ENTRE CRISTO Y LOS HOMBRES}

La teología francófona de la primera mitad del siglo XX se había centrado en la persona de Cristo, buscando las consecuencias espirituales de su unión con los hombres. El Padre Hurtado fue testigo de esta corriente en Lovaina, y debió haber reflexionado mucho acerca de este tema (30). En Puntos de Educación afirma:

[Cristo] y yo formamos realmente uno, no con unidad que destruya nuestra individualidad, ni que llegue a constituir una unión hipostática como la que existe entre las dos naturales de Cristo, pero sí con una unidad que los teólogos llaman mística, esto es, misteriosa pero no menos real que las anteriores (31).

El texto contiene varios elementos importantes. Tomando el lenguaje de la cristología clásica asegura que nuestra unión con Cristo es una unión mística, pero que no se identifica con la unión hipostática (la que se da entre divinidad y humanidad en Cristo). Se trata de una unión misteriosa pero real. La valorización del carácter 'real' de lo 'místico' posiblemente depende del concepto de mysterion en la teología de San Pablo, tan valorado por la Nouvelle Théologie. Nuevamente aparece la valoración de la teología: el modo de comprender la constitución ontológica de Cristo tiene sus repercusiones en la acción de la Iglesia.

Esta unión mística, real pero no hipostática, no destruye la individualidad. De este modo, el hombre en Cristo permanece realmente unido a Él, sin perder su propia individualidad. Aparecen dos elementos, aparentemente en tensión, que serán característicos de la espiritualidad del Padre Hurtado: la pérdida de sí mismo, por la unión, y la colaboración activa, en virtud de la propia individualidad. ¿Cómo se articula esta relación?

\section{DONACIÓN DE SÍ MISMO Y COLABORACIÓN APOSTÓLICA}

El Padre Alberto Hurtado plantea que la condición necesaria para la unión a Cristo es la donación de sí mismo:

El cristianismo es una donación total a Cristo, es un aspirar al 'vivo ego iam non ego, vivit vero in me Christus', no ser uno quien vive, sino Cristo, a mirar

(29) Nuestra imitación de Cristo, en Un disparo a la eternidad, p. 84.

(30) J. Castellón, Identificarse con Jesucristo, sirviéndolo en su misión, II, 4.2.1, p. 50 (pro manuscripto).

(31) Puntos de Educación, cap. XIV. 
las cosas de este mundo las del otro con los ojos de Cristo, a ser otro Cristo, para tener la idea de irradiar a Cristo, de pasar por el mundo haciendo el bien, como Cristo (32).

El texto vincula la donación total a Cristo con el ideal paulino de 'ser Cristo'. De este modo, para 'ser Cristo' es necesario 'perderse' en Cristo (33), tal como lo afirma en un apunte:

La divinización de nuestra alma exige previamente la pureza de corazón, el vaciarnos completamente de nosotros mismos para ser poseídos plenamente por la Gracia a fin que podamos decir: ya no soy yo quien vive, es Cristo quien vive en mí (34).

La unión con Cristo exige vaciarse de sí mismo. Lo que se opone a este don de sí mismo es el egoísmo y la sensualidad: "La antítesis del amor, que es el don de sí, [es] la sensualidad = búsqueda de sí: ama como el salteador [ama] a su víctima, para despojarla" (35). La donación debe ser total, para que Cristo viva en el cristiano: "entrega, entrega entera y total en manos de Cristo para que Él se sirva de nosotros. Que cada uno no se preste, se dé a su movimiento; ocupe su puesto con fe entera y consagración total" (36).

Tenemos, entonces, por una parte, que el ideal paulino exige la donación de sí mismo, la pérdida de sí, el vaciamiento: es la actitud expresada en la primera parte del versículo: 'ya no vivo yo'. Pero, por otra parte, esta actitud debe ser complementada por otra: la colaboración activa, que se expresa en la segunda parte del versículo: 'es Cristo que vive en mí'.

El mismo P. Hurtado que insiste en la pérdida de sí mismo, invita a colaborar con todas las cualidades personales. Por eso, según él, la humildad es: "ponerse en su sitio, tomar todo su sitio, reconocerse tan inteligente, tan virtuoso, tan hábil como uno cree serlo; darse cuenta de las superioridades que uno cree tener, pero sabiéndose en absoluta dependencia ante Dios, y que todo lo ha recibido para el bien común" (37).

Donación y colaboración; pérdida y cooperación; pequeñez y grandeza; insignificancia del instrumento y necesidad del mismo. Estos términos expresan algo de esta admirable paradoja tan afirmada por el Padre Hurtado: "Seré mucho si consiento en perderme en Cristo, en abandonarme en Él, en 'ser Él'. Vivo yo; ya no yo; vive en mí, Cristo" (38). Se llega a ser mucho cuando uno consiente en perderse: "¿Qué valgo yo? ¡Solo, nada! Pero con la bendición de Cristo, mucho. Soy Él. Vivo yo, ya no yo..." (39).

(32) Y cada día me convenzo, $A P H$ s 35 y 10.

(33) Cf. El obstáculo mayor del optimismo, $A P H$ s23 y 04

(34) La donation de soi même, $A P H$ s30 y 10.

(35) Sensualidad, $A P H$ s55 y 18

(36) Retiro a dirigentes de A.C., APH s 19 y 30

(37) Las virtudes del hombre de acción, en La búsqueda de Dios, p. 47.

(38) El obstáculo mayor del optimismo, APH s23 y 04.

(39) Beatificación Pío X, APH s54 y 25. 
Para expresar esta paradoja, el Padre Hurtado recurre a varias metáforas bíblicas y litúrgicas que destacan, por una parte, la insignificancia y pequeñez del instrumento y, por otra, la necesidad y la grandeza del mismo:

Nosotros debemos ser Cristo: como el barro para curar al sordomudo; como la gota de agua que se echa al cáliz y se transubstancia porque consiente en perderse y es divina, como el pan que alimentó a la inmensa muchedumbre (40).

Pérdida de sí y colaboración activa están en tensión, pero no son contrarias, puesto que la entrega de sí mismo se realiza en la misma colaboración apostólica: "Que cada día sea como la preparación de mi muerte entregándome minuto a minuto a la obra de cooperación que Dios me pide, cumpliendo mi misión, la que Dios espera de mí, la que no puedo hacer sino yo" (41). El que se vacía de sí mismo permite que Cristo viva en él, por ello, afirma el Padre Hurtado, podemos incluso tener 'complejo de superioridad', pues valemos mucho en la medida que Cristo vive en nosotros (42). El cristiano que está llamado a identificarse con Cristo debe 'perderse' para 'ser'.

Pero, ¿cómo ser Cristo? Es la pregunta que se hace en una plática de retiro en 1940. La respuesta más inmediata es 'imitando a Cristo', pero el Padre Hurtado siente la necesidad de precisar bien qué significa la imitación de Cristo (43).

\section{5. 'NUESTRA' IMITACIÓN DE CRISTO, 'NUESTRO MODO' DE SER CRISTO}

Alberto Hurtado recomendaba y citaba con frecuencia La imitación de Cristo de Tomás de Kempis, pero en muchos textos reacciona contra una mala comprensión de esta imitación (44). Una meditación de un retiro para profesores de la Universidad Católica, pronunciada en 1940, lleva como título 'Nuestra imitación de Cristo'. Hablar de 'Nuestra imitación' tiene un cierto matiz polémico, pues toma distancia de 'La imitación'. El Padre Hurtado insiste en que la unidad con Cristo 'no destruye nuestra individualidad' y, por tanto, la verdadera imitación, nuestra imitación, no consiste en la fría repetición de lo que Cristo hizo, sino en hacer lo que haría si estuviera en mi lugar. De hecho, insiste en algo interesante: "La Imitación [de Cristo] en alemán y en flamenco se llama: El seguimiento de Cristo" (45), lo

(40) Retiro a dirigentes de A.C., APH s19 y 30.

(41) Un disparo a la eternidad, p. 212.

(42) Cf. "Yo valgo mucho, soy muy importante, debo tener complejo de superioridad. ¿Cómo no he de valer si Cristo vive en mí, si soy miembro de su Cuerpo, mi propia cabeza es Él, mi alma el Espíritu Santo, mi papá Dios?”, Nuestra responsabilidad en la vida, APH s47 y 26.

(43) Cf. $4^{a}$ Día. Plática. ¿Cómo ser Cristo?, APH s42 y 01 i.

(44) Lo cita, lo recomienda y lo considera el libro cristiano más popular después de los Evangelios. Cf. $A P H$ s 07 y 11 ; s23 y 24 ; s32 y $14 \mathrm{~b}$; s38 y 04 ; s 45 y 06 ; s 47 y 10 ; s 49 y 20 ; s61 y 01 ; s70 y 046.

(45) Un disparo a la eternidad, p. 131: "Él vino a dar el primer paso, pero no quiso hacerlo todo por amor a mí: quiere no solo que yo lo imite, sino que obre en Él y prolongue su acción, trabajando 
que destaca el carácter personal y creativo del seguimiento, evitando así el sesgo de uniformidad del concepto de imitación, con los riesgos que comporta.

Aquí se une el teólogo con el pedagogo. Alberto Hurtado había obtenido el Doctorado en Pedagogía en Lovaina, y su formación pedagógica se aprecia en muchas afirmaciones más allá del ámbito pedagógico. Entre ellas, el respeto a la individualidad en el desarrollo de las personas. La imitación no puede centrarse en la actuación externa. Además, una imitación material de Cristo es imposible:

Y, ¿en qué consiste la imitación de Cristo? No en hacer lo que Él hizo, sino lo que haría si estuviese en mi lugar. No fue mujer, ni viejo, ni religioso bajo obediencia, ni inspector... y sin embargo [es] modelo para todos ellos (46).

Ser Cristo no significa para nosotros trasplantarnos a cultura muerta y pasada. La imitación de Cristo no es una reconstrucción histórica de la vida de nuestro Jefe. La perfección del cristiano no consiste en usar turbante, ni hablar arameo, ni en vivir a la manera de Palestina. Todas estas cosas no tienen nada que ver con la esencia de la vida de Cristo. Son accidentes que le fueron impuestos por el momento histórico en el cual se encontró (47).

No se trata, entonces, de una copia literal o mecánica de Cristo, ni una fría repetición, porque Cristo no es un recuerdo histórico lejano. Además, "la vida externa de Cristo, no es su vida" (48); se trata, más bien, de penetrar, como el artista que contempla una obra de arte, hasta captar el mismo espíritu de Jesús:

Mirarlo a Él, penetrar en sus sentimientos, en sus motivos de obrar y en la manera de realizar sus actos para poner en nuestras vidas esos mismos rasgos. La suprema aspiración de nuestra vida debe ser parecernos a Cristo, ser como Cristo, el 'vivo yo, ya no soy sino Cristo en mí', que constituía la grandeza incomparable de Pablo de Tarso. En otros términos: obrar como obraría Cristo si estuviera en mi lugar (49).

La donación de la gracia es diferente en cada persona y, por tanto, la realización del ideal paulino de 'ser Cristo' no solo acepta, sino que exige múltiples maneras de llevarse a cabo. La mencionada meditación pronunciada en la Universidad Católica (50), aborda de lleno esta temática y afirma: "Nuestra imitación de

con su impulso a sus órdenes (La Imitación en alemán y flamenco se llama: El seguimiento de Cristo). Quiere tener acciones en su cuerpo místico que no tuvo en su cuerpo mortal: quiere ser soldado, aviador, madre, universitario, jocista, envejecer, enfermar de cáncer, ser andinista, enseñar un hijo".

(46) Reino, $A P H$ s33 y 27.

(47) Lo esencial en nuestra actitud de católicos, $A P H$ s45 y 05.

(48) Lo esencial en nuestra actitud de católicos, $A P H$ s 45 y 05.

(49) Novena de Navidad, 1943. Radio Mercurio, $A P H$ s54 y 16 b.

(50) Cf. Un disparo a la eternidad, pp. 79-85. "La encarnación histórica necesariamente restringió a Cristo y su vida divino-humana a un cuadro limitado por el tiempo y el espacio. La encarnación mística, que es el cuerpo de Cristo, la Iglesia, quita esa restricción y la amplía a todos los tiempos y espacios donde hay un bautizado. La vida divina aparece en todo el mundo. El Cristo histórico fue judio viviendo en Palestina en tiempo del Imperio Romano. El Cristo místico es chileno del siglo $X X$, alemán, francés y africano... Es profesor y comerciante, es ingeniero, 
Cristo consiste en vivir la vida de Cristo, en tener esa actitud interior y exterior que en todo se conforma a la de Cristo, en hacer lo que Cristo haría si estuviese en mi lugar" (51). De este modo desemboca en la consabida pregunta ¿qué haría Cristo en mi lugar? Además de la señalada influencia de É. Mersch, se aprecia, en estos párrafos, el influjo de otro profesor de Lovaina, que posteriormente visitó Chile, en 1944: el Padre Pierre Charles (52).

Cristo está al centro de la teología y la espiritualidad, es el ambiente de la Universidad de Lovaina (53). Así lo señala Alberto Hurtado: "La espiritualidad de nuestra época se caracteriza por una feliz insistencia en el conocimiento y amor de Jesucristo, centro de toda vida espiritual. Nunca como ahora se habían publicado tantos y tan hermosos estudios sobre Jesús, cada uno reflejando un aspecto nuevo de la persona o de la vida del Maestro" (54).

\section{PROGRESO EN LA IDENTIFICACIÓN CON CRISTO}

La unión con Cristo admite diversos grados. No es una realidad que se adquiera indistintamente y de una vez y para siempre. Por tanto, se puede progresar o retroceder en esta unión.

a. El Bautismo. En el desarrollo de este proceso, los sacramentos tienen un papel importante. Naturalmente, en base a la teología sacramental clásica, el primer paso es dado en el Bautismo:

El Padre... quería llamarnos hijos, y que lo fuéramos en absoluta verdad y para eso nos quería unidos a Cristo, quería vernos en Cristo. Por el bautismo nos injertamos en Cristo... pasamos a ser miembros de su Cuerpo... pasamos a ser uno en Cristo, en cierto sentido pasamos a ser Cristo (55).

abogado y obrero, preso y monarca... Es todo cristiano que vive en gracia de Dios y que aspira a integrar su vida en las normas de la vida de Cristo, en sus secretas aspiraciones, y que aspira siempre a esto: a hacer lo que hace, como Cristo lo haría en su lugar. A enseñar la ingeniería, como Cristo la enseñaría el derecho... a hacer una operación con la delicadeza... a tratar a sus alumnos con la fuerza suave, amorosa y respetuosa de Cristo, a interesarse por ellos como Cristo se interesaría si estuviese en su lugar. A viajar como viajaría Cristo, a orar como oraría Cristo, a conducirse en política, en economía, en su vida de hogar como se conduciría Cristo”, p. 83.

(51) Un disparo a la eternidad, p. 82.

(52) Una formulación semejante a la célebre pregunta del Padre Hurtado: “QQué haría Cristo en mi lugar?" se encuentra en un libro del Padre Charles: "Imiter le Christ c'est faire ce que Jésus aurait fait s'il était à ma place, dans mes circonstances. Ce n'est pas faire ce qu'il a fait”, P. Charles, Prière de toutes les heures. Vol. I, cap. Ut enarrent mirabilia tua.

(53) Cf. J. Castellón, Identificarse con Jesucristo, sirviéndolo en su misión, II, 4.2, pp. 47-53 (pro manuscripto).

(54) Prólogo de A. Hurtado al libro de A. Goodier, Jesús resucitó, Santiago 1942.

(55) Responsabilidad frente a la Iglesia, $A P H$ s45 y 02. Además: "Desde el día del Bautismo, yo no vivo, es Cristo que vive en mí; pues la gracia bautismal me ha transformado, Dios me ha dado su propia naturaleza", APH s47 y 21; también en un retiro de Semana Santa de 1948: "Pero por el bautismo estamos en ese plano. Efectos. Nuestra incorporación real a Cristo que Jesús expresó con la metáfora de la vid y los sarmientos: participación de la misma vida; San Pablo repite con la metáfora del injerto, y luego con la del cuerpo. Somos un cuerpo; uno mismo. Pasaremos a ser 
Por el Bautismo pasamos a ser Cristo (56), uniéndonos a toda la Iglesia. Y no se trata de una relación puramente individual, tal como lo destaca en la continuación del mismo texto:

Y como la Iglesia es Cristo, nosotros somos la Iglesia. La Iglesia no es algo respetable, al servicio nuestro, pero extraño a nosotros mismos, como la Cruz Roja o la Asistencia Pública. No, la Iglesia es nosotros. Cristo y yo, y ustedes, el GRAN NOSOTROS (57).

La Iglesia es el 'gran nosotros', la unión con Cristo tiene siempre un marcado carácter eclesial. Aparece de nuevo la centralidad de la eclesiología del Cuerpo Místico de Cristo, y su carácter social.

b. La Eucaristía y el sacerdocio. La unión con la Iglesia-Cuerpo de Cristo se inicia con el Bautismo y se profundiza por la Eucaristía:

¡Ser Cristo! He aquí todo mi problema. La razón de ser de la creación. Todo el mundo ha sido creado para la gloria del Hijo de Dios, y al Hijo de Dios yo me uno por mi bautismo que me hace a mí también Hijo de Dios, y me vinculo más y más íntimamente cada vez que comulgo. Por la Eucaristía puedo yo decir con toda verdad: ¡Cristo vive en mí, yo en Él! No ser sino uno. Toda la razón de ser de mi vida, todo el sentido de mi existencia lo descubro yo y lo recuerdo cada vez que asisto a la Santa Misa, cada vez que comulgo (58).

El vínculo con Cristo admite grados, y se profundiza por medio de la Eucaristía: por la comunión, me vinculo más y más íntimamente a Cristo. El Padre Hurtado insistía en la comunión frecuente (solo en su libro Puntos de Educación, la menciona 14 veces (59)) y, junto a ello, insistía en que la comunión no es un acto mecánico o automático sino una verdadera donación de uno mismo en unión con Cristo: "Vivir nuestro día como Cristo, ser Cristo para nosotros y para los demás. Eso es comulgar" (60). Por la Eucaristía se realiza esta donación total, por ello Alberto Hurtado llama a "hacer de la Misa el centro de la vida. Prepararme a ella con mi vida interior y mis sacrificios, que serán hostia de ofrecimiento; prolongarla durante el día dejándome partir y dándome, en unión con Cristo. ;Mi Misa es mi vida, y mi vida es una Misa prolongada!" (61). Comulgar sacramentalmente, entonces, implica entregarse a los demás 'dejándose partir y dándose' en unión con Cristo. El compromiso social aparece aquí vinculado a la Eucaristía.

miembros, una misma realidad con Cristo. Él pasa a vivir en mí; yo en Él, su vida a ser la mía. Cristo vive en mí, yo en Él", APH s58 y 15.

(56) Esta afirmación deberá ser completada con otras, que se expondrán más abajo, relativas a la universalidad del 'ser Cristo' por la encarnación.

(57) Responsabilidad frente a la Iglesia, $A P H$ s 45 y 02

(58) El obstáculo mayor del optimismo, $A P H$ s23 y 04

(59) Todo el c. XXI de Puntos de Educación está dedicado a la educación eucarística de la juventud.

(60) Eucaristía Congreso, 7 de julio de 1940, APH s50 y 04.

(61) Sagrada Eucaristía, $A P H$ s50 y 22 
Comprendida de este modo, la Eucaristía verdaderamente transforma a quien la recibe; por ella, se produce un cambio en el hombre: "Después de comulgar, puede con verdad decir el joven: 'Tú en mí yo en Ti'; o como San Pablo: 'Vivo yo; ya no yo, vive Cristo en mí'” (62). Los que reciben a Cristo se transforman en Él. Y para ilustrar este cambio, Alberto Hurtado se vale de una metáfora tomada de la teología eucarística: afirma que el sacerdote, en la Misa, "aspira a ser consubstanciado con Cristo" (63); en otros lugares habla de 'transubstanciarse' en Cristo (64), y en una prédica del Mes de María en 1948, en la Iglesia de San Francisco, afirmó:

Los hombres que reciben a Cristo se transforman en Él: 'Vivo yo, ya no yo, vive Cristo en mí. Y vive en mi hermano que comulga junto a mí, y vive en todos los que participamos de Él. Formamos todos un solo Cristo viviendo su vida, realizando su misión divina. Somos una nueva humanidad, la humanidad en Cristo estrechamente unidos, más que por la sangre de familia. Por la sangre de Cristo formamos el Cuerpo místico de Cristo y en Cristo y por Cristo y para Cristo vivimos en este mundo. La salvación de la [nueva] raza no es una salvación individual, es una salvación social... ¡unión más íntima que la de todos los marxismos! (65)

Nuevamente destaca el carácter eclesial de la unión con Cristo; nuevamente la teología del Cuerpo Místico está presente. La comunión eucarística vincula más y más a Cristo y a su misión. La comunión implica 'dejarse partir y darse, en unión con Cristo'; entregarse a los demás, como Cristo (66); transformarse en Cristo, transubstanciarse en Él y prolongar su misión.

El 'ser Cristo' y la celebración eucarística tienen una especial relación con el sacerdocio. En una prédica de primera misa, el Padre Hurtado, de acuerdo a la sacramentología clásica, afirma que el sacerdote, de modo particular, está llamado a realizar, y de hecho realiza, el ideal paulino de Gál 2, 20:

El sacerdote que es, como dice S.S. Pío XI, alter Christus. El sacerdote es otro Cristo... es alguien a quien Cristo ha tomado para vivir especialmente en Él, para orar por Él, amar por Él, salvar por Él. Sacerdos alter Christus. Ayer el

(62) Educación Eucarística de la juventud, APH s50 y 02, cf. Puntos de Educación, c. XXI. En su intervención en el Congreso Eucarístico de 1940, afirmó: " $Y$ en la Eucaristía ese cambio se produce: el hombre se transforma en Dios, es asimilado por la divinidad que lo posee: puede con toda verdad decir como San Pablo: ya no vivo yo, Cristo vive en mí”, Eucaristía Congreso, 7 de julio de $1940, A P H$ s50 y 04.

(63) $A P H$ s 41 y 05.

(64) "Oh, si fuéramos a la Misa a renovar el drama sagrado: ofrecernos en el ofertorio con esas especies que van a ser transformadas en Cristo pidiendo nuestra transformación... a ser aceptados por la divinidad en la consagración, a ser transubstanciados en Cristo (ioh, si la ofrenda hubiese estado hecha a conciencia!), la consagración sería el elemento central de nuestra vida cristiana”, Eucaristía Congreso, 7 de julio de 1940, APH s50 y 04.

(65) Eucaristía, $A P H$ s58 y 18.

(66) Cf. "Y la comunión, esa donación de Cristo a nosotros que exige de nosotros gratitud profunda traería consigo una donación total de nosotros a Cristo que así se dio y a nuestros hermanos, como Cristo se dio a nosotros", Eucaristía Congreso, 7 de julio de 1940, APH s50 y 04. 
Venerado Sr. Arzobispo, Carlos, te impuso sus manos ungidas: fueron sus manos las de Cristo que te escogía para que fueras Cristo, para que en adelante pudieras decir con toda verdad: 'Vivo ego, iam non ego'... (67).

La identidad del sacerdote con Cristo es una exigencia del ministerio sacerdotal. El sacerdote solo podrá guiar a los demás hacia Cristo en la medida que él mismo sea conducido por Cristo (68).

c. La importancia de la formación. En este proceso de asimilación a Cristo, el Padre Hurtado da un importante lugar a la formación. Afirma: "Creo que las costumbres no son buenas porque las ideas están en quiebra" (69), mostrando el valor de las ideas. El conocimiento de Cristo es condición necesaria para progresar en la identificación con Él:

Así hemos de obrar con Cristo: mirarlo a Él, penetrar en sus sentimientos, en sus motivos de obrar, y en la manera de realizar sus actos para poner en nuestras vidas esos mismos rasgos. La suprema aspiración de nuestra vida debe ser: parecernos a Cristo, ser como Cristo, el 'vivo yo, ya no soy sino Cristo en mí' (70).

No basta un conocimiento superficial, desde fuera, hay que profundizar en el conocimiento de Cristo, hasta conocerlo interiormente. La pregunta ¿qué haría Cristo en mi lugar? exige un profundo conocimiento de Jesucristo, 'un hondo conocimiento de Cristo', como él mismo lo decía. Por este motivo, el Padre Hurtado fue un gran impulsor de la lectura directa de las Evangelios (71).

\section{CONSECUENCIAS DE LA UNIÓN CON CRISTO}

El ideal paulino de 'ser Cristo', expresado en Gál 2, 20, se constituye en principio orientador y unificador de la vida cristiana. Y, según las palabras del Padre Hurtado, debe ser estudiado a fondo, en todas sus consecuencias (72).

(67) Mihi vivere Christus est, $A P H$ s54 y 02.

(68) Cf. Mundo y sacerdote, $A P H$ s56 y 15.

(69) Moral Social. Punta Arenas, APH s57 y 12. Además, el largo artículo sobre la Formación sacerdotal es elocuente a este respecto, cf. La búsqueda de Dios, pp. 259-272.

(70) Novena de Navidad, 1943. Radio Mercurio, APH s54 y 16b.

(71) Así en Puntos de Educación: "La lectura del Santo Evangelio ha de recomendarse insistentemente a todos los socios de la A.C.... A todos los fieles debería aconsejarse que tuviesen el Santo Evangelio en su velador... Es imprescindible para un joven cristiano acudir a las fuentes mismas de la revelación y ponerse en contacto directo con ellas", Puntos de Educación, cap. XIV. Y se lamenta de la ignorancia del Evangelio: "¡Cuántos leen y releen los manuales, o buscan recetas, sin conocer el Evangelio, sin acordarse de San Pablo!”, La búsqueda de Dios, p. 28. Cf. APH s52 y 10a; s57 y 12 .

(72) Cf. Humanismo Social, cap. I. 


\subsection{Consecuencias pedagógicas}

Tanto la pedagogía como la moral se simplifican y adquieren unidad. En una época en que la moral y la pedagogía giraban en torno a una multitud de normas, reglas, propósitos, premios y castigos, Alberto Hurtado centra todo en Cristo:

El pedagogo cristiano ha de inspirar al niño el deseo de identificar su vida con la de Cristo, el propósito firme de aspirar siempre a decir con verdad: 'Cristo vive en mí y yo vivo en Cristo'; le inspira también las ideas fundamentales del dogma del Cuerpo místico de Cristo: cómo todos los cristianos somos solidarios, cómo nuestras buenas acciones aprovechan a todos los hombres y merecen gracias especiales de Dios, y cómo, por el contrario, el pecado es no solo un mal individual, sino también un mal social (73).

El carácter social o eclesial del ideal paulino queda nuevamente a la vista. La pedagogía cristiana, entonces, se centra en la persona de Cristo: "La verdadera educación consiste en darse a sí mismo como modelo viviente, como lección real. Jesucristo así lo hizo: 'Aprended de mí que soy manso y humilde de corazón'. 'Ven y sígueme'. 'Yo soy el Camino, la Verdad, la Vida” (74). Así, la pedagogía se simplifica al máximo: "casi la base de toda educación, es infundir en los jóvenes el amor a Jesucristo. El que ha mirado profundamente una vez siquiera los ojos de Jesús, no lo olvidará jamás” (75). De este modo Gál 2, 20 se presenta como el ideal que contiene todo el resto de los ideales.

\subsection{Consecuencias morales y ascéticas}

Algo semejante se verifica en la moral y en la ascética. La búsqueda de la santidad no consistirá, entonces, en complejas fórmulas, en propósitos aislados, o en mirarme a mí, sino en mirarlo a Él (76). Toda la vida ascética gira en torno al único ideal de 'ser Cristo':

Ponerme frente a frente de mi vocación y los pormenores que exija en cuanto a mi vida interior, vida regular, celo, etc. Pero todo esto ganará en fuerza si lo vemos no como propósitos aislados sino como peldaños para llegar a Cristo, para llegar a ser Cristo (77).

Las múltiples, y a veces complicadas, prácticas religiosas se unifican y ' $g a$ nan en fuerza' si se vinculan al único ideal de 'ser Cristo'. Alberto Hurtado, como pedagogo, tan sensible al tema de las motivaciones, alega que no se debe decir 'haz esto y evita aquello' porque sí; sino que se debe urgir al bien, porque Cristo

(73) Crisis de la pubertad y educación de la castidad, cap. Educación religiosa.

(74) Caracterizacion de la adolescencia, $A P H$ s23 y 15.

(75) El educador del espíritu, $A P H$ s20 y 15.

(76) Cf. Bienaventurados los que tienen hambre y sed de justicia, APH s36 y 11.

(77) La Transfiguración, $A P H$ s42 y $01 \mathrm{a}$. 
vive en nosotros (78). Solo un cristianismo vigoroso tendrá efectivas consecuencias morales:

Ese cristianismo de fachada no impedirá la más mínima caída sexual. Ese no es el cristianismo. El cristianismo es una donación total a Cristo, es un aspirar a realizar el ideal de San Pablo: 'Vivo yo, ya no yo: vive Cristo en mí' (79).

'Ya no vivo yo, es Cristo quien vive en mí... Y ahí está toda la moral para el niño, para el adolescente y para el hombre: adquirir conciencia de ser otro Cristo, que Cristo quiere actuar por él y su suprema aspiración: ¿Qué, haría Cristo si estuviese en mi lugar? (80)

El ideal de 'ser Cristo' tiene la fuerza necesaria para orientar la vida moral del adolescente, aun en medio de las adversidades. Y no solo la moral individual, también la moral social tiene su fundamento en Gál 2, 20:

El amor... a los suyos, como Cristo amó a su Iglesia y sé entregó por ella. El sentido social, no por miedo al comunismo, que eso no es cristiano. Aunque no hubiera un comunista en el mundo, por amor a Cristo, porque Cristo vive en mí y quiere obrar por mí. El trato con el pobre... el problema social hasta sus últimas consecuencias... (81).

El sentido social es consecuencia del dogma: No es la regla externa ni el miedo al comunismo lo que puede orientar la compleja vida de los cristianos en el mundo, es el ideal paulino lo que fundamenta una vida de entrega que no se contenta con el mínimo (evitar los pecados), sino que aspirar al máximo (la generosidad en la entrega).

\subsection{Consecuencias eclesiales o sociales: 'El pobre es Cristo'}

Al tratar la encarnación como fundamento del 'ser Cristo', nos encontramos con afirmaciones tales como: "Basta ser hombre para poder ser miembro del Cuerpo Místico de Cristo" (82), o bien, "El Hijo de Dios al unirse una naturaleza humana elevó en ella a todo el género humano" (83), idea afirmada por Gaudium et Spes $\S 22$, pero menos frecuente por aquellos años. Estas frases complementan aquellas que afirman que solo los bautizados forman parte del Cuerpo Místico de Cristo, y tienen grandes consecuencias sociales:

Mientras los católicos no hayamos tomado profundamente en serio el dogma del Cuerpo Místico de Cristo, que nos hace ver al Salvador en cada uno de

(78) Cf. Moral Social. Punta Arenas, APH s57 y 12.

(79) Crisis de la pubertad y educación de la castidad, cap. El ambiente familiar.

(80) La formación religiosa del niño en el hogar, $A P H$ s55 y 12; cf. APH s46 y 08.

(81) La formación religiosa del niño en el hogar, APH s55 y 12; cf. APH s46 y 08.

(82) Humanismo Social, cap. I; La búsqueda de Dios, p. 156; Moral Social, p. 204.

(83) Moral Social, p. 204. 
nuestros hermanos, aun en el más doliente, en el más embotado minero que masca coca, en el trabajador que ebrio yace tendido física y moralmente por su ignorancia, mientras no veamos en ellos a Cristo, nuestro problema no tiene solución. La riqueza de nuestra doctrina social reside entera en el principio de la dignidad de la persona humana en el orden natural y mucho más en su elevación al orden sobre natural (84).

La dignidad de la persona humana tiene raíces dogmáticas, su firme fundamento se encuentra en la teología de la creación a imagen y semejanza y más aún en la encarnación y, por tanto, no depende de las condiciones accidentales en que se encuentren los sujetos: "sin limitación alguna de razas, cualidades naturales, fortuna, simpatías... Basta ser hombre para poder ser miembro del Cuerpo Místico de Cristo, esto es, para poder ser Cristo” (85). La encarnación es 'irreversible', sus consecuencias se perpetúan. Esto tiene enormes efectos eclesiales y para la vida social. Con razón el Padre Hurtado considera que el dogma del Cuerpo Místico es "el más social de los dogmas" (86), y el fundamento cristológico de la intuición que guió su propia vida: "el pobre es Cristo". Son muchos los documentos que contienen esta central intuición, y la relacionan a la teología del Cuerpo Místico y con el ideal paulino del Gál 2, 20:

Cada pobre es Cristo, y por eso Saulo cuando iba por el camino de Damasco buscando cristianos que perseguir, oyó la voz: 'Saulo, Saulo, ¿por qué me persigues'? Para Cristo cada prójimo, cada hombre, es Él. Es una consecuencia del Cuerpo Místico (87).

Da consuelo pensar esa maciza realidad: el pobre es Cristo en persona. 'Lo que hiciereis a Él... a Mi' (88).

Un testimonio del P. Fernando Karadima es elocuente en este mismo sentido: "En la Población Nueva San Manuel, el Padre Hurtado entró a una choza en medio de un basural, en que vivía un grupo de personas, y comenzó a sacar unos niños para llevarlos al Hogar de Cristo. En un momento, teniendo a un niño de unos dos años en sus manos, se volvió a los jóvenes que lo acompañábamos, y levantándolo, nos dio la bendición, trazando con el niño el signo de la cruz" (89). Finalmente, el 14 de agosto de 1952, en la Clínica de la Universidad Católica, dictó esta despedida a los amigos del Hogar de Cristo, 4 días antes de su muerte:

Al partir, volviendo a mi Padre Dios, me permito confiarles un último anhelo: el que se trabaje por crear un clima de verdadero amor y respeto al pobre,

(84) La búsqueda de Dios, p. 156.

(85) La búsqueda de Dios, p. 151.

(86) Puntos de Educación, cap. XIV.

(87) Retiro sobre el Cuerpo Místico, APH s47 y 24.

(88) Carta, $A P H$ s65 y 57.

(89) Un fuego que enciende otros fuegos, p. 110. 
porque el pobre es Cristo. 'Lo que hiciereis al más pequeñito, a mí me lo hacéis'(Mt 25, 40) (90).

Estas afirmaciones tienen enormes consecuencias. Cristo se identifica con su Iglesia, pero la presencia de Cristo se dilata mucho más allá de los límites visibles de la Iglesia, lo eclesial tiende a identificarse con lo social, porque toda la humanidad algo tiene que ver con el Hijo de Dios hecho hombre. Toda la realidad adquiere un valor nuevo a la luz de Cristo: "al católico la suerte de ningún hombre le puede ser extraña" (91). Así, de un modo particular, aparece el fundamento religioso de la preocupación social.

\subsection{Identificarse con Cristo - pobre: El 'sentido del pobre':}

El ideal de 'ser Cristo' y la identificación del pobre con Cristo tienen como consecuencia, por la lógica más simple, la propia identificación con el pobre. Al parecer no hay textos explícitos en que el Padre Hurtado proponga como ideal la identificación con el pobre, pero sí se encuentran muchos que la suponen. La identificación con Cristo-pobre de la tercera manera de humildad de los Ejercicios Espirituales de San Ignacio (92), es otro elemento que fundamenta esta identificación con el pobre que es Cristo. Aquí encontramos un punto muy característico del Padre Hurtado y, por ello, vale la pena tratarlo de modo más prolijo.

a. Ningún dolor humano me es ajeno

La identificación con el que sufre es recurrente en los escritos de Alberto Hurtado. Luego de describir el dolor humano, declara: "esos dolores son nuestros, no podemos desentendernos de ellos. Nada humano me es ajeno" (93); "ningún problema humano en el fondo me puede ser extraño" (94); "al católico la suerte de ningún hombre le puede ser extraña" (95). Insiste, en muchos documentos, que el dolor del que sufre es nuestro propio dolor: "Cada prójimo, rico o pobre, [...] es mi hermano, mi auténtico hermano, más aún, es Cristo: 'Lo que hiciereis al menor de mis pequeñuelos a Mí me lo hacéis'. Dios es tan Padre suyo como mío; ambos somos hijos de María, llamados al mismo cielo y a ayudarnos en esta vida como

(90) Cartas, p. 319.

(91) Responsabilidad frente a la Iglesia, $A P H$ s 45 y 02.

(92) EE 167: " $3^{a}$ humildad. La $3^{a}$ es humildad perfectíssima, es a saber, quando incluyendo la primera y segunda, siendo igual alabanza y gloria de la divina majestad, por imitar y parescer más actualmente a Christo nuestro Señor, quiero y elijo más pobreza con Christo pobre que riqueza, oprobrios con Christo lleno dellos que honores, y desear más de ser estimado por vano y loco por Christo que primero fue tenido por tal, que por sabio ni prudente en este mundo". Cf. Un disparo a la eternidad, pp. 287-290.

(93) La búsqueda de Dios, p. 146. Resuena aquí la conocida expresión del poeta latino Terencio: "Homo sum: humani nihil a me alienum puto", es decir, "Soy hombre: considero que nada humano me es ajeno", Heautontimorumenos, Acto 1, esc. 1, línea 25. Esta idea posteriormente fue asumida por el Concilio Vaticano II, en GS, 1: "Nada hay verdaderamente humano que no encuentre eco en el corazón [de los discípulos de Cristo ]".

(94) La búsqueda de Dios, p. 114.

(95) La búsqueda de Dios, p. 137. 
hermanos que se aman. Sus dolores son mis dolores; las injusticias que él sufre las sufro yo, como decía San Pablo" (96).

La mirada del Padre Hurtado tiene como perspectiva la eternidad: 'estamos llamados al mismo cielo', lo que lejos de debilitar su compromiso, lo radicaliza. En una meditación de 1947, también expresa esta identificación en el dolor: "Amar a mis hermanos. Amarlos hasta no poder soportar sus desgracias [...] Su dolor debe hacerme mal [...] que todo lo que los disminuye, me desgarre a mí también. Que los errores anclados en su corazón me pinchen continuamente. Que las mentiras o las ilusiones con que los embriagan, me atormenten; que los periódicos materialistas con que los ilustran, me irriten" (97). Finalmente, una carta refleja una identificación aun existencial del Padre Hurtado con los pobres: "Aún quedan muchos niños debajo de los puentes y tirito al pensar cómo tiritan ellos" (98).

Una prédica por la radio, en 1944, describe los dolores de los más lejanos, nombrando incluso a los pescadores de la China, y afirma: "al pensar en ellos y en su inmensa amargura [...] entonces la comprensión del mensaje de Cristo me dice que no amo bastante, que no soy bastante hermano de todos los que sufren, que sus dolores no llegan bastante al fondo de mi alma, y quisiera, Señor, estar atormentado por hambre y sed de justicia que me torturara para desear para ellos todo el bien que apetezco para mí" (99). En un vehemente texto pronunciado en Cochabamba, en 1951, señala: Sufrimos ante el dolor de los miembros de nuestra familia, ¿pero sufrimos ante el dolor de los mineros o ante el sufrimiento de los que duermen en la calle? ¿Sufrimos ante esos miles de cesantes? ¿Nos enferma la enfermedad de los tuberculosos? Y recuerda aquellas madres que han de dar a luz en la vía pública porque, como para María, no hay sitio para ellas en parte alguna (100).

En una meditación describe las críticas de quienes atacan a los cristianos, y afirma: "El cristianismo, ¿no habrá penetrado en ellos? O bien sus quejas son un eco de la enseñanza del Crucificado... En todo caso, son mis hermanos en Cristo, y su suerte es la mía" (101). Incluso el dolor de los adversarios de la Iglesia es reflejo del dolor del Crucificado y, por tanto, el dolor del cristiano, pues, su suerte es la mía.

Datos muy significativos, a este respecto, se encuentran en un texto que es una suerte de reglamento de la Fraternidad del Hogar de Cristo, documento corregido desde su lecho de enfermo. Al explicar los votos de los miembros, se habla de "la

(96) Et eritis mihi testes, $A P H$ s58 y 08.

(97) La búsqueda de Dios, p. 62.

(98) Cartas, $A P H$ s 70 y 028.

(99) La búsqueda de Dios, p. 147.

(100) "Sufrimos ante el dolor de los miembros de nuestra familia, ¿pero sufrimos acaso ante el dolor de los mineros tratados como bestia de carga, ante el sufrimiento de miles y miles de seres que, como animalitos, duermen botados en la calle, expuestos a las inclemencias del tiempo? ¿Sufrimos acaso ante esos miles de cesantes que se trasladan de punto a punto sin tener otra fortuna que un saquito al hombro donde llevan toda su riqueza? ¿Nos parte el alma, nos enferma la enfermedad de esos millones de desnutridos, de tuberculosos, focos permanentes de contagio porque no hay ni siquiera un hospital que los reciba? ; Sufren esos cristianos, que tienen 60 y hasta 80 habitaciones destinadas a solo su persona, cuando piensan en los que no tienen ni siquiera una cama en la cual descansar, en esas madres que han de dar a luz en la vía pública, porque como para María no hay sitio para ellas en parte alguna?” La búsqueda de Dios, p. 156.

(101) La búsqueda de Dios, p. 58. 
obediencia al pobre", que describe como: "sentir sus dolores, sus angustias, como propios, no descansando mientras esté en nuestras manos ayudarlos. Desear el contacto con el pobre, sentir dolor de no ver a un pobre que representa para nosotros Cristo" (102). Todos estos textos son unánimes en afirmar que los dolores de los que sufren deben ser nuestros dolores, porque son los dolores de Cristo; que la suerte de nuestros hermanos es nuestra suerte, porque es la suerte de Cristo.

b. El sentido del pobre

En sus últimas cartas, en enero de 1952, el Padre Hurtado manifiesta su intensión de escribir algo sobre 'el sentido del pobre', algo que tiene muy adentro, donde se encuentra el núcleo del cristianismo y que se descubre en la lectura y meditación tranquila del Evangelio (103). Algunas de estas cartas solo anuncian su propósito, pero en la última, la del 8 de enero, dice 'estoy escribiendo', lo que indica que, al menos, debió comenzar a redactar. Desgraciadamente, no se conserva ningún manuscrito que aborde directamente el tema.

La expresión 'el sentido del pobre' proviene de Salmo 40, 2: 'Beatus qui intellegit super egenum et pauperem': Bienaventurado el que tiene la inteligencia del pobre (104). La primera cita con fecha segura se encuentra en Humanismo Social, publicado en 1947: "la literatura... contribuye a desarrollar en el alma el sentido de la caridad, el sentido del pobre, que tanto alaba la Sagrada Escritura: 'Bienaventurado el que tiene la inteligencia del pobre' (Sal 40,2)", y además se encuentra en un borrador anterior (¿1945?). Posteriormente, en 1951, aparece en un retiro a la Fraternidad del Hogar de Cristo, como parte del cuarto voto de quienes se integraran a la Fraternidad: "Cuarto voto: obediencia al pobre, tener el sentido del pobre" (1951) (105). Y, finalmente, en 1952, en las cartas que están citadas en la nota.

Pero, ¿qué significaba exactamente para Alberto Hurtado 'el sentido del pobre'? No hay muchos datos explícitos. Un camino se ofrece en el Retiro a la Fraternidad del Hogar de Cristo (1951), al explicar el cuarto voto, asocia 'la obediencia al pobre' con 'el sentido del pobre' (106), y en el Reglamento de la misma Fraternidad

(102) Cartas, APH s64 y 62.

(103) Efectivamente, en enero de 1952 afirma: "Estoy escribiendo un libro que llamaré Moral Social, por no llamarlo Doctrina Social Católica; y si me da el tiempo quisiera 'garabatear' algo que tengo muy adentro, 'el sentido del pobre'” (Cartas, p. 317); y a otro colaborador le anuncia: "Espero escribir este verano (¿o comenzar?) algo sobre el sentido del pobre. Yo creo que allí está el núcleo del cristianismo y cada día hay más resistencia e incomprensión a todo lo que dice pobreza" (Cartas, p. 316); el 4 de enero del mismo año afirma: "Tengo in mente dos libritos o libros?: uno sobre el sentido del pobre en el cristianismo. Quisiera hurguetear bien la Sagrada Escritura para inquirir el plan de Dios sobre el pobre y sobre la pobreza"(Cartas, APH s70 y 31); y cuatro días después: "Estoy escribiendo algo sobre "El Sentido del Pobre" y algunos punto sociales. ;Que cosas tan maravillosas se descubren en una lectura y meditación tranquila sobre el Evangelio"(Cartas, p. 317).

(104) Se trata de una deficiente traducción latina de Sal 40, 2 en base al griego de la LXX (makavrio" oJ sunivwn ejpi; dtwcovn

(105) Retiro a las Sras. del Hogar de Cristo, APH s47 y 16.

(106) Cf. "Cuarto voto: obediencia al pobre, tener el sentido del pobre", Retiro a las Sras. del Hogar de Cristo, APH s47 y 16. 
(1952), describe la obediencia al pobre como, "sentir sus dolores, sus angustias, como propios; no descansando mientras esté en nuestras manos ayudarlos. Desear el contacto con el pobre, sentir dolor de no ver a un pobre que representa para nosotros Cristo", lo que podría constituir una definición aproximativa. Así, el sentido del pobre significaría la capacidad de identificarse con el pobre (sus dolores son mis dolores), de identificar al pobre con Cristo (el pobre es Cristo), y de actuar coherentemente con lo anterior (no descansando...).

Otro camino para comprender el significado de la expresión lo otorga el paralelismo entre 'el sentido del pobre' y 'el sentido de Dios'. En sus últimos años, el Padre Hurtado insistió muchísimo en el grave riesgo de la pérdida del sentido de Dios. Tres componentes colaboran en el desarrollo de este concepto: el primero y más importante es la Carta de cuaresma de 1948 del Cardenal Suhard, Le sens de Dieu, luego las actas de una reunión de Maestros de Novicios jesuitas del 16 y 17 de abril de 1947, de varias provincias europeas (107) y, finalmente, las conversaciones del P. Hurtado con J. Maritain en octubre de 1947 en Roma (108), en las que el filósofo francés "se lamentaba como del mayor peligro del olvido de la contemplación” (109). Un documento redactado en 1948 que lleva este mismo título (110), indica que 'el sentido de Dios' es la sensibilidad para captar la grandeza de Dios, su Majestad, su Soberanía; para interesarse por Dios en sí mismo, para alabarlo y adorarlo; para descubrir en la fe el absoluto de Dios, y actuar de acuerdo a ello. De este modo, 'el sentido del pobre' significaría la capacidad de interesarse por el pobre, de descubrir en la fe su verdadera identidad, es decir, que 'el pobre es Cristo', y vivir de acuerdo a ello.

A estos caminos se podría agregar un tercer paralelismo: la 'devoción al pobre' (111). Esta expresión requiere una mirada de fe: "Tener devoción a cualquier santo no cuesta nada (...). Tenerles devoción cariñosa [a los pobres], confieso que es difícil" (112). Para ello, afirma el Padre Hurtado, es necesario tener espíritu sobrenatural.

De este modo, nos encontramos frente a tres expresiones que suponen el mismo paralelismo: el 'sentido del pobre', la 'obediencia al pobre', y la 'devoción al pobre'. Todas ellas implican una visión de fe que descubre al pobre como sacramento de Cristo. Sin una mirada religiosa del pobre, estas expresiones carecen de verdadero sentido.

Nuevas pistas sobre el significado del 'sentido del pobre' se encuentran en la prédica que Mons. Manuel Larraín pronunció en el funeral del Padre Hurtado. Afirma que los orígenes del 'sentido del pobre' de Alberto Hurtado se encuentran en su labor en el Patronato de San Antonio, junto a su madre, la Señora Ana Cruchaga.

(107) Cf. Reunión de Padres Maestros de Novicios, APH s59 y 09.

(108) Durante su estadía en Roma, en 1947 el Padre Hurtado junto a Manuel Larraín visitaron a Jacques Maritain. Cf. La búsqueda de Dios p. 288.

(109) El sentido de Dios, APH s45 y 10.

(110) Cf. El sentido de Dios, APH s45 y 10.

(111) El Padre Hurtado toma esta expresión de un sermón de Bossuet, y la expone en un retiro, cf. Nuestra responsabilidad en la vida, $A P H$ s 47 y 26.

(112) Nuestra responsabilidad en la vida, $A P H$ s 47 y 26. 
Relaciona la expresión con el mismo Salmo: "beatus qui intelligit super egenum et pauperem" $(40,2)$, y asocia 'el sentido del pobre' con la capacidad de reconocer a Cristo en el pobre y actuar consecuentemente:

¡El sentido del pobre! En ellos vio a Cristo. En sus llagas curó las del Maestro. En sus miembros ateridos cubrió la desnudez de Jesús. Y hace dos días, me atrevo a decirlo con íntima certeza, allá en los cielos resonó con especial acento la voz del Juez Supremo que dictaba su sentencia de eternidad: 'Ven, bendito de mi Padre, a poseer el reino que tenía preparado. Era peregrino sin techo y me recibiste. Estaba desnudo y me vestiste. Enfermo y me visitaste. Hambriento y me diste de comer. Tuviste el sentido del pobre. Lo que hiciste a uno de esos desvalidos, me lo hiciste a Mí. Entra en el gozo de tu Señor' (113).

Estos caminos se complementan y permiten comprender con mayor precisión el significado de la expresión estudiada. Podemos afirmar que 'el sentido del pobre' consiste la sensibilidad para reconocer a Cristo en el pobre, experimentar sus dolores como propios y actuar coherentemente. El sentido del pobre no es una mera aceptación intelectual, incluye ciertamente un aspecto teórico: el reconocimiento de Cristo en el pobre, pero además otro práctico: la actuación coherente con la convicción anterior, que se ve radicalizada por el llamado de Pablo a 'ser Cristo', es decir, a identificarse con Cristo que se identifica con el pobre.

\section{CONCLUSIÓN}

Luego de este largo recorrido, una breve conclusión. En primer lugar, se confirma la centralidad del ideal paulino de Gál 2, 20 como eje unificador de la vida cristiana del Padre Alberto Hurtado. Sus múltiples afirmaciones en este sentido son elocuentes.

Por otra parte, aparece claro que la admirable acción del Padre Hurtado no es fruto de un mero entusiasmo afectivo o de una benevolencia puramente humana, sino que tiene sólidas raíces tanto espirituales como teológicas. La acción de Alberto Hurtado está fundamentada en contundentes bases teológicas. Es un sacerdote que 'piensa la acción', que mira teológicamente la realidad y sabe sacar las consecuencias del estudio del dogma. Se entiende mejor, así, su gran valoración por los estudios, aun en medio de una vida activa sumamente exigente.

Finalmente, se destaca el carácter religioso de la orientación social del ministerio sacerdotal de Alberto Hurtado. Una mala comprensión de este punto lleva a la falsa disyuntiva que se pregunta: el Padre Hurtado, ¿espiritual o social? Como si para destacar su dimensión social fuera necesario reducir su dimensión espiritual o, al contrario, se requiriera disminuir su carácter social para destacar su profundidad espiritual. El recorrido anterior muestra que el carácter religioso, particularmente cristológico, no solo no debilita, sino que radicaliza su acción social, porque 'el

(113) M. Larraín, Oración fúnebre. 
pobre es Cristo'. El compromiso con la justicia se hace más urgente, porque 'el pobre es Cristo'. El ideal paulino de identificarse con Cristo, de 'ser Cristo', lo arrastra a una entrega mucho más generosa en busca del beneficio total de sus hermanos y, en especial, de los pobres. Solo la visión de fe sobrenatural, que permite reconocer a Cristo en cada hombre, en especial en los más pobres, es capaz de sostener una vida de entrega tan generosa, tan profunda, $\tan$ inteligente, tan cristalina y tan constante como la del Padre Alberto Hurtado, que vivió eucarísticamente, 'dejándose partir y dándose, en unión con Cristo'.

No es necesario, entonces, optar entre el social y el espiritual. El mismo que invita a los jóvenes a la comunión frecuente de los miembros de la Acción Católica es el que insiste en el cumplimiento de los deberes sociales. El Padre Hurtado se comprometió de modo tan radical a la solución de los graves problemas de la sociedad de su época, precisamente porque era un hombre profundamente identificado con Cristo.

No hay motivo más radical para entregarse a los demás y comprometerse en la solución de sus dolores que reconocer en ellos, por la luz de la fe, a Cristo mismo. El ideal de 'ser Cristo' no tiene nada de inofensivo.

\section{RESUMEN}

En los escritos de Alberto Hurtado, el versículo bíblico citado con mayor frecuencia es Gálatas 2, 20: "Vivo yo, ya no yo, es Cristo que vive en mí. Y en muchos escritos, el Padre Hurtado destaca la centralidad de este ideal paulino en la espiritualidad cristiana: "Qué simple resulta nuestra espiritualidad Ser Cristo!". Estas observaciones indican a Gál 2, 20 como la clave de la espiritualidad del santo jesuita.

El presente artículo ofrece una presentación sistemática del contenido de Gál 2, 20 en los escritos del Padre Hurtado, en búsqueda de una clave que permita comprender la espiritualidad, y más ampliamente vida, del santo jesuita.

La identificación con Cristo, propuesta por Gálatas 2, 20, constituye esta clave que conjuga el ideal paulino de 'ser Cristo'con el reconocimiento de Cristo en el otro, en especial el pobre, propuesto por la teología del Cuerpo Místico.

\section{ABSTRACT}

In the writings of Alberto Hurtado, the most frequently-cited biblical verse is Galatians 2: 20, "I live now not with my own life but with the life of Christ who lives in me..." In many writings, as well, Father Hurtado emphasizes the centrality of this Pauline ideal in Christian spirituality: "How simple our spirituality becomes! To be Christ." These observations indicate that Gal 2: 20 is the key to the spirituality of the Jesuit saint.

The present article offers a systematic presentation of the content of Gal 2: 20 in the writings of Father Hurtado, in order to find a key that permits one to understand the spirituality, and in a wider sense, the life of the Jesuit saint.

Identification with Christ, proposed by Gal 2: 20, constitutes this key that conjugates the Pauline ideal of "being Christ" with the recognition of Christ in the other, especially the poor, proposed by the theology of the Mystical Body. 